\title{
Aristotle's Doctrine of the Mean and the Circularity of Human Nature
}

Nahum Brown

\begin{abstract}
Aristotle's famous claim that human beings are animals with rationality has a subtle and complicated articulation in his doctrine of the mean. This paper offers textual analysis of Aristotle's discussion of the mean as a resource for coming to terms with the thesis that humans naturally deliberate over the essence of their nature. Unlike other animals who tend to act without deliberation and without mediation, human beings are the animals who are capable of giving an account of themselves. However, this also means that human beings are the animals whose nature it is to give an account. This paper proposes that Aristotle's doctrine of the mean, as it is found in the Nicomachean Ethics, helps to explain this circular, and in some ways puzzling, tension between having a nature and giving an account of one's nature.
\end{abstract}

Keywords: Aristotle, the mean, human nature, logos

1 ristotle's famous claim that human beings are animals with 1 rationality ${ }^{1}$ has a subtle and complicated articulation in his 1 discussion of the mean. To be the kind of animal that has rationality is to express a tension between phusis ( $\varphi$ v́rıs), which is usually translated as

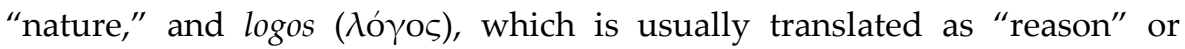
"account." Unlike other animals who tend to act without deliberation and without mediation, human beings are animals capable of giving an account of their nature. However, this also means that human beings are the animals whose nature it is to give an account. I propose in this paper that Aristotle's doctrine of the mean, as it is found in the Nicomachean Ethics, ${ }^{2}$ offers a number

${ }^{1}$ This claim appears in a number of places throughout Aristotle's corpus, including in book 1.13 of the Nicomachean Ethics, where Aristotle distinguishes between rational and irrational elements of the soul (1102a5-1103a13). In this article, I will use the abbreviation CWA followed by the Bekker numbering system for Aristotle, The Complete Works of Aristotle, 2 volumes, ed. by Jonathan Barnes (Princeton: Princeton University Press, 1984).

2 Aristotle also discusses the mean in the Eudemian Ethics. For analysis of the relation between the Nichomachean Ethics and the Eudemian Ethics in terms of the mean, see Ioannis D.

(c) 2016 Nahum Brown

http://www.kritike.org/journal/issue_19/brown_december2016.pdf

ISSN 1908-7330

(cc) $\mathrm{BY}-\mathrm{NC}-\mathrm{ND}$ 
of resources for explaining this circular, and in some ways puzzling, tension between having a nature and giving an account of one's nature.

Before I explore how the mean expresses itself in the tension between phusis and logos, I will begin by giving some background by explaining Aristotle's point about the mean generally. In book 2.6 of the Nicomachean Ethics, Aristotle says that the one who is virtuous knows how to find the mean between the extremes of vice. The one who is virtuous knows how to feel and act just right in accordance with this mean, that is, how to be at the right time, act with the right force, give not too much and not too little, as each situation requires. To emphasize Aristotle's conclusions, first, I will define the mean, as Aristotle does, as an intermediary between deficiency and excess. Second, I will show that excellence is prior to the extremes and that being excellent is about doing what one naturally does well. Third, I will explain why Aristotle calls virtue a state of character. Fourth, I will contrast moral and intellectual virtues in order to expose why it is the moral virtues that are characterized by a mean. And fifth, I will clear up a certain misconception about what a mean really is, by showing that Aristotle does not necessarily think that we should act temperately in every situation, but rather that we should act in just the right way. This analysis should help us to establish the argument for why measuring what is just right is an expression of logos. My aim, then, is to expose a connection between place, choice, and the mean in order to articulate the thesis about why finding and choosing our nature is so complicated. Throughout this analysis, I comment on why moral virtues are characterized by a mean, and I situate Aristotle's point within a larger discussion about how we are the animals who take account. By proceeding in this way, my aim is to explain that when we attempt to act in accordance with the mean, we also attempt to express a productive, circular tension between phusis and logos.

"Excellence," Aristotle says, "is a kind of mean." ${ }^{3}$ And a mean is a disposition set between two other extreme dispositions. Both extremes are vices. One vice is deficiency, the other is excess. Excellence acts as the medium position equidistant between the two vices. ${ }^{4}$ So if a person exhibits

Evrigenis, "The Doctrine of the Mean in Aristotle's Ethical and Political Theory," in History of Political Thought, 20:3 (1999).

${ }^{3}$ Aristotle, CWA 1106b27- b28.

${ }^{4}$ Joe Mintoff entertains an objection about multiple vices. Why should the mean always only generate two vices? Why can there not be many vices instead of just two? While this objection is interesting and could lead to fresh interpretations about Aristotle's claim that virtue is singular and vice is multiple (Aristotle, CWA 1106b29- b34), my sense is that this objection does not take seriously enough that with the mean Aristotle has presented us with a philosophy of being between, and that being between requires the contrary poles of excess and deficiency, not a multiplicity, but a duality of vices. For Mintoff's discussion of this objection, see Joe Mintoff, "On the Quantitative doctrine of the Mean," in The Southern Journal of Philosophy, 51: 4 (2013), 449. 
courage in a given situation, this is excellent because courage acts as the mean between the two vices of fear, on the one hand, which is the deficiency of courage, and rashness, on the other, which is its excess.

Anything that can be divided in this way generates all three dispositions, and yet the mean is really prior to the vices, since it is the mean by which we gauge the identity of a thing, and since the vices are really just extremes or mistakes of this identity. The mean is really the measure because when we say that a thing does what it does excellently, this is also a way to describe that a thing is what it is by fulfilling its nature. ${ }^{5}$ Aristotle gives an example of a horse. ${ }^{6}$ If a horse is excellent, this means that it is both excellent at being a horse, at exhibiting its nature, and that it is also excellent at what it does, at running, carrying, etc. Excellence acts as the measure of what the horse is. If we do not know the details of what makes a horse excellent, then we do not really have a sufficient sense of what a horse is about. So, what is important about Aristotle's example of the horse is that we can infer two interrelated points: (1) When something is excellent, this means that it satisfies its nature, that it is good at what it is and at the work it does. It is the mean by which we measure both the thing's functions and its identity. And (2) just as the identity of a thing is prior to the accidents and immaturities of its identity, likewise, the mean is prior to the extremes.

Since excellence is a precise disposition set between the two extremes, we have to develop enough sensitivity to exhibit the mean and fulfill our nature. Aristotle says that we are not automatically endowed with this sensitivity, but rather that excellence is a state of character that we can develop over time by forming good habits. A person who feels and acts well begins, as he or she grows mature, to form an excellent state of character. Now, Aristotle clarifies that of the three parts of the soul, excellence is a state and not a passion or a faculty. This is the case because a person who is excellent must choose to be excellent, whereas a person driven by appetite or someone who makes use of a faculty does not exercise choice. Aristotle also explains that not all states of character are excellent. Not all people can find and choose the mean. Some miss the mark or lack control or simply want to be vicious. And some do not even know what is right from wrong. Aristotle gives an extensive list of six states of character later in book 7.1 of the Nicomachean Ethics when he contrasts a person of super-human excellence with one who is brutish, a person of human excellence with one who is vicious, and a person of continence with one who is indulgent and lacks

${ }^{5}$ For an expanded discussion of the concept of the good in Aristotle and how this relates not only to the mean but also to self-sufficiency, order, and determinateness, see Christopher V. Mirus, "Order and the Determinate: The Good as a Metaphysical Concept in Aristotle," in The Review of Metaphysics, 65:3 (2012), 499-523.

${ }^{6}$ Aristotle, CWA 1106b2- b4.

(C) 2016 Nahum Brown

http://www.kritike.org/journal/issue_19/brown_december2016.pdf

ISSN 1908-7330

(c) BY-NC-ND 
control. ${ }^{7}$ I will leave the details of these six states of character for another discussion, but I do want us to notice a few points. One is that a person who has an excellent state of character both wants to do what is right and, indeed, does what is right. This is the case because an excellent person can find the mean, measure the mean, and act in accordance with it, whereas every other state of character, with the exception of God-like excellence, fails in one way or another either to want it or to act it out. It is important to notice that both the truly virtuous and the truly vicious share a certain commonality in that they both do what they want, whereas those who either have or lack control feel conflicted and suffer from the urges of what they do not want. Although the virtuous and the self-controlled both act well, the latter's state of character is marred by not entirely wanting to act well. But then, since the vicious person really wants to act badly, in other respects this person is as far from excellence as one can be, with the exception of the brute, who is sub-human and cannot even distinguish between right and wrong.

Although a person may know what is right, this person may still not feel compelled to do what is right, or may suffer from contrary urges, which oppose the person's rationality and cause him or her to act inappropriately. This happens because the intellectual virtues and the moral virtues work differently and are not always aligned. ${ }^{8}$ Even though a person may be well educated and may know how to act just right, this person may have developed poor habits and may do what is wrong. Aristotle claims that knowing what is right is not enough. A person also needs to feel compelled to do what is right; moreover, this person needs to want to feel this compulsion. Only the truly virtuous really follows the mean and is excellent, since it is only the virtuous who wants to feel compelled to act well. So, whereas the intellectual virtues are about knowing what is excellent in principle and in itself, the moral virtues are about developing good habits that prompt us, not only to act well, but to want to act well. Thus, it is the moral virtues that are characterized by the mean, because it is the moral side that deals with how to make the irrational parts of our lives correspond with what we know is right. It is not enough to know what excellence is. We need to practice excellence as well. To act in accordance with the mean is to have

\footnotetext{
${ }^{7}$ Aristotle, CWA 1145a14- b21.

${ }^{8}$ That the intellectual and the moral virtues are not always aligned becomes even more pronounced in Book X of the Nichomachean Ethics, where Aristotle claims that the intellectual virtues lead to a higher form of happiness than the moral (practical) virtues. For an examination of the division of different levels of happiness in Aristotle, see Nathan Colaner, "Aristotle on Human Lives and Human Natures," History of Philosophy Quarterly, Vol. 29, No. 3, 2012. For a contrast with Colaner's examination of the happiness that comes from intellectual verses moral virtues, also see Jonathan Lear, Aristotle: The Desire to Understand (Cambridge: Cambridge University Press, 1994).
} 
developed habits that allow us to be sensitive to what is right, not just in a general way, but in a practical way. ${ }^{9}$

Now I would like to clear up a misconception that might otherwise obscure Aristotle's point about the relationship between the mean and human nature. When Aristotle says that excellence is the medium position between two extreme vices, this should not be understood as to always act in a mediocre or temperate way. Part of this confusion comes about because temperance itself is one of the most prominent expressions of the mean. Furthermore, the word "mean" suggests moderation as part of its definition, which contributes to the misconception that to act in accordance with the mean is to act in a mediocre way. But Aristotle's point is different. What Aristotle has in mind is that we should act in just the right way, just as the situation requires of us. If courage is what is right in a given circumstance, then acting with gentle moderation would be out-of-place, since strong decisiveness is what the situation requires. Thus, we should be careful not to assume that the mean between two extreme vices is always a form of moderation.

Aristotle says that excellence is a mean that is relative to us, one which is not true for everyone at all times, but is rather true in a very precise way. ${ }^{10}$ We should be careful not to conflate the mean that is relative to us and the mathematical version of the mean. A mathematical mean is true for everyone at all times. For example, the mathematical mean between the numbers 2 and 6 is always 4 . But a mean that is relative to us is only true insofar as it fits the exact specificities of the situation. There is no universal rule or principle, which one could apply throughout in any given circumstance, that would always make something excellent. In book 2.6 of the Nicomachean Ethics, Aristotle gives the example of the gigantic Milo and the slim athlete. ${ }^{11}$ The portion of food that is just right for Milo would be significantly larger than the portion of food that is just right for the athlete. Both can eat too much or too little, but the point is that what is too much or too little is different for each. If we confuse acting in accordance with a mean and acting in a mediocre way, we might think that both the giant Milo and the slim athlete should eat the same mediocre amount. But Aristotle's point is that they should both eat what is appropriate. If the athlete is on a special diet and needs to eat a limited portion of food, then this is what is just right.

9 Mariska Leunissen outlines how physiology also plays an important role in Aristotle's theory of moral character. See Mariska Leunissen, "Aristotle on the Natural Character and Its Implications for Moral Development," in Journal of the History of Philosophy, 50:4 (2012), 507-530.

${ }^{10}$ Howard J. Curzer outlines and criticizes two major interpretations of Aristotle's claim that the mean is relative to us: "Character Relativity" and "Role Relativity." See Howard J. Curzer, "Aristotle's Mean Relative to Us," American Catholic Philosophical Quarterly, 80:4 (2012).

${ }^{11}$ Aristotle, CWA 1106b1- b7.

(C) 2016 Nahum Brown

http://www.kritike.org/journal/issue_19/brown_december2016.pdf

ISSN 1908-7330

(cc) BY-NC-ND 
Milo's huge portion of food, on the other hand, is still a medium amount equidistant between the extremes, and yet it is not a medium portion of food in the sense of moderation, and certainly not in contrast to the slim athlete's portion.

All of this shows that it is a virtuous person who knows how to go to the right place relative to the situation. So, another way to talk about how to measure what is just right relative to us is in terms of Aristotle's notion of place, what he refers to in the Physics book 4 as topos, ${ }^{12}$ Place is both what contains us, what surrounds us, what gives us our points of reference, and yet place is also where we tend to go of our nature. In other words, place has at least two connotations, both of which are important to Aristotle's doctrine of the mean: (1) As a container, place acts as the boundary or limit of each situation, giving us the space and relationality with which to pivot and to measure what is just right. Yet, (2) place is also a way to express whether we are acting in accordance with the mean, since it would be appropriate to go to the place where we naturally belong, and inappropriate to fall out-of-place. Since a more in-depth exploration of the relationship between these two connotations of place and Aristotle's doctrine of the mean would be beyond the scope of this analysis, I will make just one point, which is, that a virtuous person is the one who goes to the appropriate place. A virtuous person both knows how to find the mean and tends of his or her own nature to choose the mean. Or, in other words, excellence is what both contains us and draws us towards it as what is the most natural place for us - as the fulfillment of our nature.

And yet Aristotle says that this place of excellence is difficult and singular, whereas vice is easy and multiple. This is the case because there is only one way to be virtuous; all other actions are out-of-place, either to a lesser or greater extent; they are either excessive or deficient, either too much or too little. To find the mean and to choose it is the most particular task. Although it contains us, and although we tend towards it in order to fulfill our nature, still it is precisely excellence that is the most difficult thing to give an account of. This is why Aristotle says that "it is possible to fail in many ways ..., while to succeed is possible only in one way, for which reason one is easy and the other difficult-to miss the mark easy, to hit it difficult."13 Since it is very hard to find the one out of the many, the excellent is something

12 See especially book 4 of Aristotle's Physics, 208a26-213a10. For a comprehensive account of Aristotle's conception of place, see Edward S. Casey "Place as Container: Aristotle's Physics" chapter of The Fate of Place: A Philosophical History (Berkeley: University of California Press, 1997).

${ }^{13}$ Aristotle, CWA 1106b29- b34. In the midst of his comparison of the Aristotelian mean with the Confucian mean, Jiyuan Yu offers a helpful analysis about marksmanship in terms of the mean. See See Jiyuan Yu, "The Aristotelian Mean and Confucian Mean," in Journal of Chinese Philosophy, 29:3 (2002), 337-354. 
that we must choose to find, whereas to miss what is excellent is more easy to produce since it is almost everywhere, and since we do not need to choose it in order to exhibit it. When I say that acting in accordance with the mean is how we fulfill our nature, I do not want to suggest that excellence is something that appears easily or without effort. Rather, excellence is something that we labor to find and choose in each case. We should also notice, however, that although Aristotle explains that virtue is singular and vice is multiple, this does not necessarily mean that to miss the mark is always to be vicious. Sometimes, as Aristotle notes in book 2.9, it is better to aim at the lesser extreme, rather than to miss the mark altogether. ${ }^{14}$ Moreover, sometimes we can only gauge what the mean is about by experiencing the lesser extreme and then turning towards the mean as an amendment.

What our analysis shows is that because our nature is mixed up with being virtuous, this labor to find the mean is simply what we do as what is most natural for us. We are the ones who must choose what is most difficult. But what is most difficult is just what we naturally are. To choose what is most difficult is to choose to be what we naturally are. We are the ones who must choose to go to the place where we naturally go. We are the ones whose place it is to choose. We are the animals who have logos, who give an account. We are the ones who are anxious about what it means to be. We are the ones who deliberate over how to act well. Such deliberation is a deliberation of choice, of whether we will be excellent or fall short of this. Such deliberation is an expression of the constitutive tension between phusis and logos. There are at least two registers of this tension: (1) we are the ones who give an account of our nature, and at the same time (2) we are the ones whose nature it is to give an account. Notice the subtle difference here: we are ones who are anxious about our own nature, yet it is our nature that makes us anxious. There is an important circularity that marks this tension. I say that it is important because it is this circularity that allows us to critique ourselves and to become excellent, and it is this circularity that allows us to do this naturally simply as what we are. Expressing this circularity is what the mean is all about.

If we were not of this sort, we would not need to worry about how to act. We would not need to have an ethics. We would simply do what it is that we do. But since we are the ones who take account, our nature is not as simple as it is for other forms of life. Whereas other forms of life immediately act in accordance with their nature, we complicate this by mediating what it means to be ourselves. This mediation comes as a question, an anxiety, a deliberation. In one sense, the mediation is a sort of weakness, since we are the ones who must work hard just to satisfy what it means to be. For other

${ }^{14}$ Aristotle, CWA 1109b1- b2 (approximately).

(C) 2016 Nahum Brown

http://www.kritike.org/journal/issue_19/brown_december2016.pdf

ISSN 1908-7330

(c) BY-NC-ND 
forms of life, there is no question about whether they will be what they are. They simply act, and by acting, they simply satisfy their natures. But in another sense, the mediation is a sort of strength, since we are the ones who can choose to build our lives in just the right way, who have the chance to find what is excellent. The tension between phusis and logos makes our lives so risky, since we are the ones who can fail at being what we are, and yet, at the same time, we are the ones who can succeed and flourish. Paradoxically, it is only in the sense of risking whether we will fulfill our nature that we actually do fulfill our nature.

Another way to show this tension and circularity between our nature and our account of our nature is in terms of potentiality (dunamis) and actuality (energia). ${ }^{15}$ For other forms of life, there is no margin between the potentialities of their nature and the actualization of these possibilities. This is the case because there is no mediation between doing and being. Whenever they act, this is in accordance with their nature, since there is a certain explicit necessity, which, on the one hand, lets them actualize their potentialities with ease, but, on the other hand, gives them no choice but to be what they are. We are different because there is a great margin of risk between the potentialities of who we are and the successful actualization of these potentialities. Yet, in another sense, we are not different. We are just what we are. By deliberating over what it means to actualize the extent of our potentialities, we are just naturally doing what we do. The risk that we will not be what we are is really an expression of what we are. In other words, this tension and circularity shows us that our nature is various, that there are many ways to miss the mark of what our nature can do, but that if we try to become sensitive to what is just right in each situation of our lives, we can learn to act virtuously; in other words, we can satisfy our nature, we can actualize our potential, which is just what we are.

This paradox of having a nature and of giving an account of one's nature reveals itself most explicitly in the character of the virtuous person. The virtuous person comes to habituate acting well and finding the mean in such an automatic and routine way that the complex deliberations over our nature become, for this rare and exemplary person, the most natural, fluid disposition possible. By forming excellent habits, the truly virtuous person turns the anxieties at the root of human deliberation into the unflinching courage of the heroic perfection of human nature. The virtuous character is exemplary of the circular tension between logos and phusis, since what becomes automatic and natural does not exactly render us without further mediation or deliberation, but rather naturalizes the simple desire toward

${ }^{15}$ Aristotle's treatment of the modal categories appears in book 9 of the Metaphysics, 1045b28- 1052a14. 
deliberation over what is best in accordance with the mean in a given situation. It is, in effect, the urge and act of deliberation that becomes effortless for the truly virtuous person. This does not exactly mean that the virtuous person resembles those character types from book 7.1 who feel conflicted and suffer from the urges of what they know they should not do, who either have or lack control. That deliberation comes naturally to the virtuous person is an effect, instead, of acting in accordance with the mean. This sort of deliberation over our nature is not the same kind of deliberation that the one who has or lacks control embodies, but is of an altogether different kind, since the virtuous person has learned to habitualize the precision that comes from the anxiety of human nature. The kind of deliberation that the virtuous person encounters, then, is the theme for ethics itself, not an indecisiveness about whether to do what is right or not, which would conflate the virtuous with the personalities that have or lack control, but rather a recognition of human complexity. This is also not to say that the virtuous character corrects or releases us from the circular tension between phusis and logos. While people who have or lack control exhibit deliberation overtly in the internal conflicts that they embody within themselves, the virtuous person exhibits this deliberation from a significantly different standpoint-from the unhesitating certainty of one who engages with deliberation head-on, fearlessly but steadily, in accordance with the mean.

Aristotle's doctrine of the mean is that by which we attempt to express the tension of our nature. However, since this tension is really in itself just the expression of our nature, what the mean exposes is the productive circularity of this nature. On the one hand, there is the tendency to judge what is just right. On the other hand, this same tendency to judge is simply what we do. But since the mean is something difficult that we have to choose in each case, we cannot simply apply the mean in an automatic or general way, as if by applying a rule that would be true for everyone at all times, we would resolve the tension of our nature and become excellent throughout. The mean involves judgment that is relative to each situation. The one who is excellent is the one who does not separate virtue and judgment, but has rather developed a sensitivity to what is just right. Therefore, the one who is excellent is the one who can express in the best way that our nature is about deliberation. The one who is excellent is the one who can expose this circularity, who both naturally deliberates, and at the same time deliberates over what is natural. What this analysis has shown is that the mean itself is the productivity of this circularity. It is that by which we inquire into the nature of being human, which is, at the same time, the fulfillment of this nature.

Division of Humanities, Hong Kong University of Science and Technology

(C) 2016 Nahum Brown

http://www.kritike.org/journal/issue_19/brown_december2016.pdf

ISSN 1908-7330

(c) $)$ BY-NC-ND 


\section{References}

Aristotle, The Complete Works of Aristotle, vol. 1, ed. by Jonathan Barnes (Princeton: Princeton University Press, 1984).

The Complete Works of Aristotle, vol. 2, ed. by Jonathan Barnes (Princeton: Princeton University Press, 1984).

Casey, Edward S., The Fate of Place: A Philosophical History (Berkeley: University of California Press, 1997).

Colaner, Nathan, "Aristotle on Human Lives and Human Natures," in History of Philosophy Quarterly, 29:3 (2012).

Curzer, Howard J., "Aristotle's Mean Relative to Us," in American Catholic Philosophical Quarterly, 80:4 (2012).

Evrigenis, Ioannis D., "The Doctrine of the Mean in Aristotle's Ethical and Political Theory," in History of Political Thought, 20:3 (1999).

Lear, Jonathan, Aristotle: The Desire to Understand (Cambridge: Cambridge University Press, 1994).

Leunissen, Mariska, "Aristotle on the Natural Character and Its Implications for Moral Development," in Journal of the History of Philosophy, 50:4 (2012).

Mintoff, Joe, "On the Quantitative doctrine of the Mean," in The Southern Journal of Philosophy, 51:4 (2013).

Mirus, Christopher V., "Order and the Determinate: The Good as a Metaphysical Concept in Aristotle," in The Review of Metaphysics, 65:3 (2012).

Yu, Jiyuan, "The Aristotelian Mean and Confucian Mean," in Journal of Chinese Philosophy, 29:3 (2002). 